Kenneth M. Coleman, Jonathan D. Coleman

y José Miguel Cruz²

\title{
Actitudes hacia la integración económica: datos de El Salvador y Costa Rica en 1994
}

\section{Introducción.}

\subsection{Marco teórico.}

$\mathrm{E}$

1 liderazgo puede tener gran efecto en la opinión pública sobre un tópico tan intrincado como es la integración económica regional. Después de décadas de un nacionalismo económico el cual parecía arraigado profundamente en la experiencia nacional, el ex-presidente mexicano, Carlos Salinas de Gortari, vendió a partir de $\mathbf{1 9 8 8}$ una visión de cómo iba a mejorar la economía de México por participar en un amplio Tratado de Libre Comercio (TLC) con los Estados Unidos y Canadá. En los Estados Unidos el tratado se aprobó en oclubre de 1993 y entró en vigor el primer día de 1994, provocando, entre otras cosas, el estallido de la rebelión zapatista en la región de Chiapas en México.

Las encuestas de opinión pública en México revelaron un descenso lento del apoyo para el TLC aún antes del brote de la rebelión zapatista y un temor especialmente marcado entre el sector campesino3; pero la realidad es que Carlos Salinas de Gortari y las élites políticas y económicas mexicanas vendieron, por sus acciones conjuntas, la idea de ingresar en el TLC, cambiando así una postura proteccionista y nacionalista del gobiemo mexicano durante varias décadas. El liderazgo afectó, por los menos durante algunos años, la opinión pública mexicana sobre la integración económica con su vecino del norte, un país hacia el cual México ha exhibido tradicionalmente una postura defensiva.

Esta experiencia mexicana ilustra un punto básico de un libro reciente escrito por John Zaller, quien insiste que la opinión pública se forma principalmente por los recados recibidos de élites políticas en su discurso público a través de los medios de comunicación social4. En caso de recibir recados unidireccionales de las élites -es decir, si todas las élites están a favor o en contra de una medida determinada de la política pública-, la opinión pública va a conformarsc a los señales que recibe de las élites. En caso de recibir recados bidireccionales - 
esto es, si algunas élites están a favor y otras en contra de una medida determinada-, o multidireccionales -es decir, si hay varios "lados" defendidos por diversas élites-, la opinión pública puede polarizarse, según la capacidad variable de los miembros del público para "leer" las fuentes de información en que más confian. Resulta que cuando las élites difieren entre sí, distintos grupos del público varían en sus respuestas, algunos alineándose a la perspectiva de sus figuras favoritas, mientras otros responden esencialmente al azar por no haber captado ninguna perspectiva coherente de los dirigentes5.

Se puede recurrir a la teoría de Zaller para explicar las variaciones en la opinión pública de dos países centroamericanos acerca de la integración regional. Uno de estos países, Costa Rica, tradicionalmente ha exhibido menos entusiasmo para la integración regional de cualquier tipo, sea política o meramente económica, como se verá más adelante. A pesar del hecho de que su ex-presidente, Oscar Arias (1986-1990), premiado Nobel por sus esfuerzos en ganar la paz centroamericana, tomó un papel de liderazgo en iniciar las reuniones presidenciales centroamericanos a partir de 1986 y en reactivar al comercio regional, la Asamblea Legislativa de Costa Rica siempre ha mostrado mucho más recelo hacia las ideas integracionistas. Ni Arias ni ningún presidente costaricense subsecuente (Rafael Calderón Foumier, 1990-1994, y José Figueres Olsen, 1994 - presente) ha sido capaz de convencer a su Asamblea Legislativa de aprobar la legislación que permita la participación coslarricense en el Parlamento Centroamericano. Es decir, las élites ticas parecen estar muy divididas sobre las formas de integración que van más allá que la mera reaclivación comercial.

En cambio, el caso de El Salvador ha sido escogido precisamente por su contraste con el caso de Costa Rica. En la historia de los esfuerzos integracionistas previos a las guerras de los 1980 , El Salvador había sido considerado como uno de los "ganadores" del comercio intrarregional. Aunque la guerra civil salvadoreña impidió parcialmente la reactivación del comercio regional por parte de El Salvador hasta 1992, no habían desacuerdos entre los dirigentes salvadoreños sobre la deseabilidad de la participación nacional en los esfuerzos regionalistas. Tanto el gobierno de José Napoleón Duarte, el de Alfredo Cristiani y el actual de Calderón Sol, con Asambleas Legislativas distintas, han hecho esfuerzos para reactivar al comercio intrarregional y participar en la construcción de nuevas instituciones para aquel fin; como el Sistema de Integración Centroamericana (SICA, con sede en San Salvador) y el Parlamento Centroamericano (PARLACEN)6. Las elites salvadoreñas parecen estar mucho más unificadas sobre la integración regional, y ni siquiera la entrada de la izquierda al sistema político a través de las elecciones de 1994 ha cambiado esta unidad aparente.

\subsection{Historia de esfuerzos integracionistas.}

Puesto que los países centroamericanos nacieron de la desintegración de la 
Federación Centroamericana en 1838, siempre han existido personas visionarias quienes han pretendido reunificar al istmo. Dependiendo de cómo se define un intento de reunificación, un conteo de tales intentos a partir de 1839 podría llegar a 25 casos.

La unión fracasó rolundamente en 1838, y los estados individuales se separaron y se fueron por sus propias vías. De 1842 a 1975 , la idea de restablecer la República Federal de Centroamérica nunca ha desaparecido totalmente... En 25 ocasiones distintas, pasos formales y oficiales se tomaron para reconstituir los estados separados en alguna unidad común de gobiemo. Ningún esfuerzo duró más de unos meses ni incluyó a todas las cinco naciones. (Hasta 1975) nunca ha habido algún esfuerzo exitoso...7

El historiador Thomas Kames explica los fracasos anteriores a la ronda más reciente (1986 - ) de esfuerzos integracionistas en términos de tres factores: (i) el fracaso de esfuerzos integracionistas ha sido un fracaso asociado a la falta de gobiernos representativos y democráticos8; (ii) el problema del "nacionalismo excesivo" y (iii) el problema del "aislacionismo de Costa Rica". A nosotros nos parece que en vez de un "nacionalismo excesivo" tendría mayor sentido hablar de un "exceso de provincialismo". Si se concibe a Centroamérica como una sola nación, luego el problema ha sido la identificación subnacional - no nacionalismo, sino subnacionalismo-. Pero el problema, cualquiera que sea el nombre aplicado, es real, como veremos abajo. En cuanto al problema de Costa Rica, vale citar textualmente otra vez a Karnes, escribiendo en 1975.

El coslarricense cree sin lugar a dudas que sus escuelas son las mejores, que su tasa de alfabetismo es la mejor y que sus elecciones son las más democráticas en Centroamérica. No quiere arriesgar los logros de su país por un exceso de intercambio con países que él considera subdesarrollados. Luego, puesto que Costa Rica es el único país centroamericano donde predominan los ciudadanos de ascendencia europea, calladamente concluye el costaricense de que los indios y mestizos en los otros países son inestables, mal instruidos y serían socios inapropiados en cualquier asamblea representativa compartida. En fin, la idea de la federación no se ha muerto en Costa Rica, pero es poco intensa para generar los votos y sobrepasar el requisito de dos tercios de la Asamblea Legislativa para proponer cambios constitucionales y otros dos tercios de una asamblea especial llamada para aprobarlos.9

A pesar de estos tres impedimentos tradicionales, el esfuerzo integracionista fue retomado de forma más enfocada y modesta en las décadas de los cincuenta y sesenta. Una serie de tratados bilaterales en los años cincuenta precedieron a la firma de tratados multilaterales en 1958 y 196010 . El propósito de estos esfuerzos era aumentar el comercio intrarregional y buscar una integración económica, sin pretender llegar a una incorporación política. 


\section{Historia comercial.}

El comercio intrarregional crecí́ rápidamente en los 60 y 70. De dos a cinco años después de la firma del Tratado General en 1960, el comercio dentro de la región aumentó anualmente de $37 \%$ en 1962, a $41 \%$ en 1963, 48\% en 1964 y $28 \%$ en 1965 . Habían algunos problemas. Honduras y Nicaragua se beneficiaron menos que otros países de ese crecimientol1. Además, el comercio regional no podía resolver el problema demográfico de El Salvador, que era fuente de migración hacia Honduras. Pero hasta la mal denominada "Guerra del Fútbol" en 1968, el crecimiento del comercio intrarregional en el Mercado Común Centroamericano era impresionante y aún después, hasta los años $\mathbf{8 0}$.

En el Cuadro 1 vemos que han sido tres las etapas del comercio intrarregional centroamericano después de 1968: (i) una etapa (1970-1980) de gran crecimiento, con un promedio anual de crecimiento comercial en la región del $+16 \%$; (ii) una etapa de deterioro económico ocasionado por las tres guerras civiles en la región y su consecuente flujo de capital, conduciendo a un decremento anual del comercio intrarregional que llegó a un promedio anual de -13\% entre 1981 y 1986; y (iii), la reactivación, empezando en 1987 y corriendo hasta el presente, que produce un incremento anual de comercio intrarregional del $+13 \%$. Se debe entender que las encuestas que vamos a analizar en el presente artículo se hicieron durante el octavo año de reactivación del comercio intrantegional; más o menos en el momento cuando el nivel de intercambio regional iba acercándose a su máximo histórico (de 1980). En este momento, no hay razones para dudar que el comercio en la región podría continuar expandiéndose.

\subsection{Muestras.}

Dadas las suposiciones respecto a las diferencias en las actitudes hacia la integración entre los salvadoreños y los costaricenses, podemos comparar los datos de dos encuestas nacionales. La primera se hizo en Cosla Rica con una muestra urbana de 593 casos en el mes de mayo de 1994 realizada por la empresa UNIMER, una empresa comercial dirigida por investigadores quienes han servido como profesores de metodología de la investigación en la Universidad de Costa Rica. La segunda encuesta fue hecha en El Salvador en el mes de octubre de 1994 por el Instituto Universilario de Opinión Pública (IUDOP) de la Universidad Centroamericana (UCA) de El Salvador, en un estudio colaborativo entre el IUDOP e investigadores de la Universidad de Nuevo México. La muestra era más grande en este caso, de unas 1,224 entrevistas. Se puede suponer un enor muestral de $\pm 4 \%$ en El Salvador y de $\pm 6 \%$ en Cosla Rica.

\section{Los resultados comparativos}

En el Cuadro 2, se puede ver que ni los salvadoreños ni los costarricenses confían netamente en los otros gobiernos centroamericanos. Los salvadoreños 


\section{Cuadro 1:}

Variaciones anuales en el intercambio comercial centroamericano, 1970-1993 (En millones de dólares)*

\begin{tabular}{lcccc}
\hline Año & Exportaciones & Importaciones & Tolal & $\begin{array}{c}\text { Cambio } \\
\text { porcentual }\end{array}$ \\
\hline 1970 & 286.3 & 299.3 & 585.6 & \\
1971 & 272.7 & 276.4 & 549.1 & $-6.2 \%$ \\
1972 & 304.7 & 306.7 & 611.4 & $+11.3 \%$ \\
1973 & 383.3 & 388.2 & 711.5 & $+26.2 \%$ \\
1974 & 532.5 & 526.0 & 1058.5 & $+37.2 \%$ \\
1975 & 536.4 & 519.1 & 1055.5 & $+0.3 \%$ \\
1976 & 649.3 & 611.3 & 1260.6 & $+19.4 \%$ \\
1977 & 789.9 & 719.8 & 1509.7 & $+19.7 \%$ \\
1978 & 862.5 & 886.3 & 1748.8 & $+15.8 \%$ \\
1979 & 879.6 & 879.8 & 1759.4 & $+0.6 \%$ \\
1980 & 1177.8 & 1177.9 & 2355.7 & $+33.9 \%$ \\
1981 & 936.8 & 972.4 & 1909.2 & $-15.4 \%$ \\
1982 & 765.5 & 796.9 & 1562.4 & $-18.2 \%$ \\
1983 & 766.7 & 811.0 & 1577.7 & $+1.0 \%$ \\
1984 & 719.7 & 724.5 & 1444.2 & $-8.5 \%$ \\
1985 & 490.3 & 538.2 & 1028.5 & $+28.5 \%$ \\
1986 & $413.0 *$ & $462.0 * *$ & $875.0 * *$ & $-14.9 \%$ \\
1987 & 487.0 & 485.0 & 972.0 & $+11.1 \%$ \\
1988 & 553.0 & 557.0 & 1110.0 & $+14.2 \%$ \\
1989 & 635.0 & 624.0 & 1259.0 & $+13.4 \%$ \\
1990 & 668.0 & 630.0 & 1298.0 & $+3.1 \%$ \\
1991 & 779.0 & 791.0 & 1570.0 & $+21.0 \%$ \\
1992 & 892.0 & 885.0 & 1777.0 & $+13.2 \%$ \\
1993 & & & & $+13.7 \%$ \\
\hline
\end{tabular}

- Fuentes: 1970-1985: Mitchell Seligson y Ricardo Cordova M., "Integration and Disintegration of Regionalism in Central America: From 1950 to 1991," en Joaquin Roy, compilador, The Reconstruction of Central America: The Role of the European Community (Miami: University of Miami, North-South Center, Iberian Studies Institule and European Community Research Institute, 1992). Estos datos se compilaron de fuentes originales en SIECA, CEPAL y INTAL.

1986-1992: Victor Bulmer-Thomas, "Los escollos de la integración," Centroamérica 1994: Anuario CRIES (Managua: Coordinadora Regional de Investigación Socio-Económico, 1994).

1993: Secrelaría Permanente del Tralado General de Integración Económica Centroamericana, "Evolución económica de los países centroamericanos durante 1993 y perspectivas para 1994", documento inédito, página 17.

- Los dalos 1982-1992 vienen de una fuente que proporcionó los dalos en millones de dólares cn cifras redondas. Las dos fuentes principales (Seligson y Cordova, Bulmer-Thomas) cubrieron los años 1980 a 1985, y coincidieron (dentro de un millon de dólares) para cada año entre 1981 y 1985, haciendo probable que una metodología semejante fuera utilizada durante lodos los años 1981-1992. Las eslimaciones de SIECA para 1991 y 1992 eran sistemáticamente más altas que las estimaciones de Bulmer-Thomas para los mismos años, por lo cual hemos incluido únicamente el cambio porcentual y no las cifras en dolares. 
exhiben mucha mayor confianza que los de Cosla Rica, pero aún en El Salvador ningún otro gobiemo merece la confianza de más que un tercio de los ciudadanos (en este caso un tercio de los salvadoreños confían en el gobiemo de Costa Rica). En lo peor de casos, menos del $16 \%$ de los salvadoreños confía en el gobiemo de Nicaragua.

Pero las aclitudes de los costarticenses hacia otros gobiemos son pésimas, mucho más negalivas que las opiniones de los salvadoreños. Un 16\% de "confianza" es la marca más positiva otorgada por los ticos hacia un gobiemo regional, el gobiemo de Panamá12. Y únicamente un 3.5\% confió en el gobiemo nicaragüense de Violeta Chamorro. En fin, los ticos sencillamente no confian en otros gobiemos centroamericanos. En este caso, puede ser que únicamente los presidentes costarricenses estén ofreciendo señales positivas a la ciudadanía, puesto que no hay apoyo equivalente para la integración en la Asamblea costarricense.

\section{Cuadro 2}

Porcentajes de salvadoreños y costarricenses diciendo que "confían mucho" o que "confian" en los gobiernos centroamericanos (1994)

\begin{tabular}{lcc}
\hline & Salvadoreños & Cosiarricenses \\
\hline Gobierno de: & & \\
Costa Rica & $33.7 \%$ & \\
El Salvador & $48.8 \%$ & $5.7 \%$ \\
Guatemala & $22.3 \%$ & $8.1 \%$ \\
Honduras & $18.7 \%$ & $9.9 \%$ \\
Nicaragua & $15.9 \%$ & $3.5 \%$ \\
Panamá & $24.0 \%$ & $16.4 \%$ \\
\hline
\end{tabular}

Fucntes: Encuestas nacionales hechas por el IUDOP en El Salvador (oclubre de 1994; tamaño de muestra $=1224$ ) y por la cmpresa UNIMER, C.A. en Costa Rica ( mayo de 1994; lamaño de mucstra $=593$ ).

- No se aplicó la pregunta sobre su propio gobierno a los costarricenses.

Lo visto en Cuadro 2 sugiere que las élites no pueden lidear fácilmente si existen patrones culturales de desconfianza. Como el ya citado libro de Kames indica, la historia de intentos de reintegrar a Centroamérica después de 1838 ha sido "una historia de fracasos". Obviamente, la desconfianza entre centroamericanos tiene raíces muy profundas que ni la intención activa de las élites podrá sobreponer fácilmente. Llama la atención que un $49 \%$ de los salvadoreños "confiaban mucho" o "confiaban" en su propio gobiemo en octubre de 1994, una cifra $16 \%$ más alta que el grado de confianza exhibido hacia el gobierno regional que quedó en segundo lugar en aquella encuesta. Dado que el gobierno salvadoreño ha tenido muchos cuestionamientos por parte de sus ciudadanos 13 , 
éste es un testimonio devastador de la falta de fe de los salvadoreños en otros gobiemos regionales. $Y$ la situación es mucho peor entre los costarricenses 14.

En el Cuadro 3 (formulaciones abstraclas), se puede observar que a pesar de la falta de confianza en los gobiemos regionales, a un nivel de abstracción hay bastante apoyo en los dos países para la integración regional. Una clara mayoría de los ciudadanos de los dos países apoyan planteamientos abstractos sobre la integración regional. En dos indicadores distintos, el porcentaje apoyando la integración centroamericana es alrededor de $61 \%$ o $62 \%$ entre los costarricenses. En los mismos indicadores en El Salvador, el porcentaje apoyando a la integración llega a 75\% y $80 \%$.

Pero cuando se trata de proponer metas muchos más concretas, una brecha notable se abre entre los salvadoreños y los costarricenses. Por ejemplo, un $76 \%$ de los salvadoreños favorece el uso de la cédula de identidad nacional como el único documento necesario para cruzar las fronteras nacionales -dejando de lado los pasaportes-; mientras que únicamente un $20 \%$ de los costarricenses hubiera apoyado tal cosa en 1994 . Un 59\% de los salvadoreños estuvo dispuesto a apoyar el establecimiento de una sola moneda centroamericana, mientras sólo 39\% de los ticos pensó que esto sería bueno. Y sobre la meta de un sólo país centroamericano, la brecha se abrió aún más, con un $56 \%$ de los salvadoreños pensando que se debe buscar tal objetivo, mientras menos del $12 \%$ de los ticos pensó en forma igual.

\section{Cuadro 3}

Porcentajes de salvadoreños y costarricenses que dicen estar "muy de acuerdo" o "de acuerdo" con varios planteamientos sobre la integración centroomericanos (1994)

Salvadoreños Costarricenses

\section{Formulaciones abstractas}

A favor de la inlegración económica centroamericana

$75.0 \%$

$61.2 \%$

Los problemas internos de Centroamérica mejorarían

con la inlegración

$80.0 \%$

$62.6 \%$

Metas de mayor especificidad

Cruzar fronteras con cédula y sin pasaporle $\quad 76.0 \% \quad 20.1 \%$

Establecer una sola moneda

$59.1 \% \quad 39.0 \%$

Meta eventual de un país único

$55.5 \%$

$11.8 \%$

Furentes: Encuestas nacionales hechas por IUDOP en El Salvador (octubre de 1994; tamaño de muesıra $=1224$ ) y por la empresa UNIMER en Costa Rica (mayo de 1994; tamaño de muestra $=593$ ). 
La importancia del liderazgo se puede apreciar por el hecho de que en El Salvador hay una diferencia estadísticamente significativa entre el estrato socio-económico alto y los demás estratos sociales cuando se trata del apoyo a la integración (medido a través de la primera formulación abstracta en Cuadro 3). Hay un $54 \%$ de personas del estrato alto "apoyando fuertemente" a la integración regional, mientras que tal grado de apoyo nunca sobrepasó a un $34 \%$ en los otros estratos sociales. En Costa Rica, no había ninguna diferencia estadísticamente significativa de tal indicador entre las clases sociales, el grado de "apoyo fuerte" nunca sobrepasó a un $22 \%$, y el grado de apoyo en el estrato alto llegó únicamente a un $12 \% 15$.

En el Cuadro 4, se presentan resultados que pueden parecer un poco inconsistentes. Los datos se refieren a la cantidad de trabajo que los gobiemos deben invertir en lograr la integración regional. La primera pregunta sugiere que el gobiemo propio (salvadoreño o costarricense, según la encuesta) debe trabajar "fuertemente" para lograr la integración regional. En este caso, los resultados eran bien parecidos a las formulaciones abstractas en el cuadro anterior (Cuadro 3), con 78.5\% de los salvadoreños pensando que su gobiemo debe trabajar "fuertemente" para lograr la meta, mientras que un $63.7 \%$ de los costarricenses opin6 de la misma forma. Pero en la formulación cautelosa, indicando que "el movimiento hacia la integración debe ir lentamente", un 53\% de los salvadoreños estuvo de acuerdo al igual que un $55 \%$ de los costarricenses. Las respuestas a la segunda pregunta pueden ser consistentes con las a la primera, si la gente sostiene imágenes de un proceso largo y lento de negociación, en el cual los gobiernos deben de trabajar fuertemente para lograr resultados óptimos.

\section{Cuadro 4 \\ Porcentajes de salvadoreños y costarricenses \\ que dicen estar "muy de acuerdo" o "de acuerdo" con que su gobierno trabaje fuerte para lograr la integración centroamericana y con que el proceso de integración debe ir lentamente (1994)}

\begin{tabular}{lcc}
\hline & Salvadoreños* & Coslarricenses** \\
\hline Formulación positiva & $78.5 \%$ & $63.7 \%$ \\
Formulación cautelosa & $53.0 \%$ & $55.3 \%$ \\
\hline
\end{tabular}

Fuentes: Encuestas nacionales hechas por IUDOP en El Salvador (octubre de 1994; tamaño de muestra $=1224$ ) y por la empresa UNIMER en Cosia Rica (mayo de 1994; tamaño de muesira $=593$ ).

- Porcentaje de salvadoreños que "no sabe": formulación positiva (6.4\%); formulación cautelosa (9.3\%).

" Porcentaje de costarricenses que "no sabe": formulación posiliva (2.2\%); formulación cautelosa (4.0\%). 
De los datos disponibles, no podemos confirmar esta suposición, que parece ser la imagen más probable que los ciudadanos de los dos países podrían tener en la mente. Sin embargo, vale notar que entre el grado de esfuerzo que la gente quiere imputar a su gobiemo y el nivel de cautela que piensa que sería lo indicado, no hay grandes diferencias entre los costarricenses y los salvadoreños. En los dos casos, la gente quiere ver esfuerzos serios en buscar la integración y cautela en negociarla.

De nuevo, en el Cuadro 5, se encuentran resultados semejantes en los dos países, con una distribución semejante de ventajas y desventajas percibidas en la integración regional por los ciudadanos salvadoreños y costarricenses. Quizás los dalos más importantes del cuadro en cuestión es la razón entre los que no ven "ninguna desventaja" y los que no ven "ninguna ventaja" en los dos países. En El Salvador, esta razón sobrepasa $10: 1(30.8 \%$ a $2.7 \%)$ mientras que en Costa Rica es mucho más modesta, 2:1 (21.2\% a 9.4\%). Sin embargo, en los dos país hay muchas más personas quienes no ven ninguna desventaja en la integración regional que las que no ven ninguna ventaja16.

Entre las ventajas mencionadas, se nota una distribución semejante entre los encuestados de los dos países, con ventajas macroeconómicas atribuidas a la integración (mejor economía, desarrollo, progreso), junto con ventajas comerciales (mayor comercio, mayor exportación), efectos esperados en el consumo (bajar precios, menos escasez de productos), y efectos sociales (abrir fuentes de trabajo, libertad de viajar) recibiendo menciones frecuentes. Sin embargo, los de Costa Rica mencionan "ventajas sociales" menos frecuentemente que los salvadoreños.

Las distribución de desventajas percibidas ilustra elemenlos compartidos entre salvadoreños y ticos y elementos particulares. Hay menciones de desventajas macroeconómicas temidas (saturación del mercados nacionales, temor de devaluaciones), desventajas microeconómicas (falta de oportunidad personal) y problemas sociales ("invasiones territoriales" o problemas raciales) en los dos países en proporciones semejantes. Las preocupaciones que distinguen a los costarricenses son sus temores de las desigualdades entre las economías centroamericanas y la posibilidad de enfrentar "problemas políticos". Dado que hay cierta historia que fundamenta estos temores, tales son previsibles. Es decir, dado que las economías de Costa Rica y Panamá exhiben no sólo mayor producto bruto per cápita que los países vecinos, sino también una distribución más equitativa del ingreso, los costarricenses quizás tengan razón para temer que un flujo libre de mano de obra atraería muchos otros centroamericanos a su país. Y, dada la estabilidad política y la vida democrática que Costa Rica ha gozado desde 1948, se puede prever la cautela de los ticos hacia las ideas de integración política con países donde la democracia está menos consolidada17. 


\section{Cuadro 5 \\ Principales ventajas y desventajas percibidas \\ por los salvadoreños y costarricenses en \\ la integración económica regional (1994)}

$\begin{array}{lrr} & \text { Salvadoreños } & \text { Costaricen } \\ \text { Ventajas } & & \\ \quad \text { Ninguna } & 2.7 \% & 9.4 \% \\ \text { "No sabe" } & 16.2 \% & 17.9 \% \\ \text { Ventajas macroeconómicas } & 26.2 \% & 25.1 \% \\ \text { Ventajas comerciales } & 26.1 \% & 31.5 \% \\ \text { Efectos en consumo } & 10.4 \% & 11.0 \% \\ \text { Ventajas sociales } & 17.4 \% & 3.5 \% \\ & & \\ \text { Desventajas } & & \\ \text { Ninguna } & 30.8 \% & 21.2 \% \\ \text { "No sabe" } & 39.2 \% & 28.8 \% \\ \text { Desventajas macroeconómicas } & 11.5 \% & 9.6 \% \\ \text { Desventajas microeconómicas } & 3.6 \% & 3.4 \% \\ \text { Desigualdad de las economías } & 1.0 \% & 7.1 \% \\ \text { Problemas políticos } & 2.5 \% & 18.4 \% \\ \text { Problemas sociales } & 10.7 \% & 8.4 \%\end{array}$

Fuentes: Encucstas nacionales hechas por IUDOP en El Salvador (octubre de 1994; tamaño de mucstra $=1224$ ) y por la empresa UNIMER en Costa Rica (mayo dc 1994; tamaño de mucstra $=593$ ).

Las implicaciones de esta perspectiva costarticense se pueden ver en el Cuadro 6, que describe las actitudes de los ciudadanos de ambos países acerca de la posibilidad de integrarse comercialmente con países extra-regionales, específicamente México y los Estados Unidos. En el momento de realización de las encuestas, la Cumbre de Miami no había ocurrido todavía y el presidente Clinton no había hecho su propuesta para iniciar las discusiones sobre un área hemisférica de libre comercio por el año 2005. En todas las preguntas, se detecta un mayor grado (aunque ligeramente mayor) de apertura de los costarricenses hacia los gobiernos de México y los Estados Unidos y hacia la posibilidad de afiliarse al Tratado de Libre Comercio entre Canadá, México y los Estados Unidos. En realidad, lo más claro es que una amplia mayoría de los ciudadanos de ambos países hubiera apoyado un ingreso de su país en el TLC en 1994 (70\% de los salvadoreños y 79\% de los costarricenses). No obstante, hay una diferencia sistemática, aunque leve, entre las respuestas de los salvadoreños y de los costarricenses. Sin oponerse a la integración regional, los costarricen- 
ses exhiben mayor interés en las opciones extrarregionales que los salvadoreños 18. Sin oponerse a opciones extrarregionales, los salvadoreños parecen exhibir mayor interés en las opciones regionales, quizás por haber tenido experiencias profundamente ambivalentes con los EE.UU. en un pasado no muy distante y con México en un pasado mucho más lejano.

\section{Cuadro 6}

Opiniones de salvadoreños y costarricenses sobre la integración extra-regional y los países hemisféricos con los cuales sería posible buscar la integración económica* (1994)

\begin{tabular}{lcc}
\hline & Salvadoreños & Costarricenses \\
\hline $\begin{array}{l}\text { Se puede "confiar mucho" o "confiar" } \\
\text { en los gobiernos de } \\
\quad \text { México } \\
\quad \text { EE.UU. }\end{array}$ & $30.0 \%$ & \\
& $46.1 \%$ & $37.1 \%$ \\
"Muy de acuerdo" o "de acuerdo" con & & $53.2 \%$ \\
la idea de incluir al país como miembro & & \\
$T L C:$ EUA-Canada-México. & $70.3 \%$ & $79.2 \%$ \\
\hline
\end{tabular}

Fuentes: Encuestas nacionales hechas por IUDOP en El Salvador (octubre de 1994; tamaño de muestra $=1224$ ) y por la empresa UNIMER en Costa Rica (mayo de 1994; tamaño de muestra $=593$ ).

- Las dos encuestas se hicieron unos meses antes de la cumbre de Miami donde se planteó la idea de una organización hemisférica de libre comercio.

\section{Conclusiones}

Estos datos de El Salvador y de Costa Rica conforman a lo que hubiéramos supuesto dada la teoría de Zaller sobre la capacidad de las élites políticas y económicas para estructurar a la opinión pública, sin dejar de lado el papel que han jugado estas naciones en la historia centroamericana. La población costarricense ha recibido recados mucho más ambivalentes de sus dirigentes que los que la población salvadoreña recibe de sus élites polílicas y económicas. Precisamente por esa ambigüedad, la capacidad de las presidencias costarricenses para lidear es menor. La estructura de la opinión pública masiva en Costa Rica hacia la integración económica muestra mucha mayor ambivalencia. La confianza en los gobiernos vecinos es pésima; la creencias abstractas a favor de la integración son mayorilarias (61-62\%), pero no son abrumadoramente favorables y cuando se habla de metas mas allá que la mera integración comercial, el apoyo mayoritario se desvanece. En contraste, los salvadoreños apoyan fuertemente a la meta 
abstracta de la integración (a niveles de 75\% a $80 \%$ ), apoyan metas específicas mayoritariamente (a niveles entre $56 \%$ y $76 \%$ ), pero exhiben bastantes dudas sobre la "confiabilidad" de gobiemos vecinos en América Central. Las élites salvadoreñas ofrecen interpretaciones generalmente más positivas hacia la integración regional - por lo menos han estado dispuestas a elegir representantes al PARLACEN desde hace 1991, algo que el gobiemo de Costa Rica todavía no ha aceptado hacer. En cambio, una serie de presidentes costarricenses ha abogado por una participación mayor de su país en el proceso de integración centroamericana, y en un caso - Oscar Arias - ha mostrado un liderazgo importante en tal proceso; pero los presidentes ticos siempre han tenido que enfrentar a una Asamblea Legislativa recelosa. Frente a recados mixtos de su liderazgo, los costaricenses no apoyan fuertemente a los procesos integracionistas.

Más allá de la teoría de Zaller, se puede invocar otras explicaciones para interpretar estos resultados - lanto variables culturales como estructurales. El historiador ya mencionado, Thomas Kames, sugiere una explicación culturalque los ticos "siempre han sido así, convencidos de ser superiores y sospechosos de los otros centroamericanos". Bien podría ser, pero en cualquier caso habria que explicar porqué las élites salvadoreñas exhiben tanta unidad acerca de la integración regional -aún cuando una mayoría substancial de su pueblo desconfía en todos los otros gobiernos regionales - y porqué no se encuentra la unidad equivalente entre las élites costarricenses. Ahí parece que la complejidad estruclural del ambiente socio-político incide. En El Salvador, inclusive con sus nuevas estructuras nominalmente democráticas, persiste la influencia de una élite comercial-financiera a través del partido ARENA en la toma de decisiones públicas. La Asamblea Legislativa salvadoreña no ha logrado el grado de autonomía lograda por la Asamblea Legislativa costarricense19, ni tampoco las instituciones públicas salvadoreñas han logrado el grado de autonomía logrado por las instituciones homólogas costarricenses frente a los grupos económicamente más poderosos. Por eso, las élites salvadoreñas pueden conducir la opinión pública más fácilmente porque hay menos disidencia entre las cúpulas.

Mucho queda para investigar sobre la opinión pública hacia la integración regional y la integración hemisférica. Con este aporte preliminar, pretendemos abrir la investigación necesaria, no cerrarla. Por ejemplo, no sabemos hasta qué grado la experiencia personal puede incidir en las actitudes: ¿los que han viajado o vivido en otro país centroamericano van a tener actitudes más positivas hacia la integración? Ni tampoco sabemos si una presencia reconocida de productos centroamericanos en el trabajo de un obrero o comerciante tendría efeclos en sus actitudes: ¿si uno vende productos centroamericanos o trabaja con materiales centroamericanos, va a tener actitudes más positivas? Tampoco sabemos mucho sobre cómo las actitudes hacia la integración regional o hemisférica pueden estar relacionadas o no con otras preocupaciones de los ciudadanos - la violencia y la delincuencia, la disponibilidad de empleos, la consolidación democrática en va- 
rios países centroamericanos, entre otras cosas-. Lo que sí sabemos es que el proceso de integración va adelante y que la opinión pública acerca de la misma es una de las dimensiones que merece investigación adicional.

\section{Notas.}

1. Agradecemos a UNIMER y especialmente a su directora, la Dra. Haydée Mendiola, y a la Universidad de Nuevo México (EE.UU.), especialmente a su Departamento de Ciencias Políticas y a su Escuela de Administración, por haber patrocinado las encuestas que hicieron posible este análisis. Jonathan Coleman agradece al Institute for International Education por una beca Fulbright que hizo posible su estadía en Costa Rica en 1993-1994 y su trabajo con UNIMER.

2. Afiliados respectivamente a la Universidad de Nuevo México (Albuquerque, EE.UU.), al Janus Capital Corporation (Denver, EE.UU.) y al Instituto Universilario de Opinión Pública de la UCA.

3. De conversaciones personales sostenidas con Miguel Basáñez, presidente de Market Opinion and Research International de México (MORI), en varias ocasiones entre 1993 y 1995. MORI hizo varias encueslas sobre el TLC.

4. The Nature and Origins of Mass Opinion (Cambridge y Nueva York: Cambridge University Press, 1992).

5. La teoría de Zaller es bastante complicada, porque de cuatro axiomas fundamentales, deriva unas 50 deducciones. Sin embargo, este párrafo presenta algunos elementos esenciales de su teoría.

6. Al elegir sus delegados en 1991, El Salvador estaba entre los primeros países en indicar su deseo de participar en el Parlamento Centroamericano.

7. Thomas Kames, The Failure of Union: Central America, 1824-1975, second edition (Tempe, Arizona: Center for Latin American Studies, Arizona State University, 1976), pág. 248.

8. Por lo cual la ronda más reciente podría ser la ronda más alentadora.

9. Ibid., pág. 255.

10. Los dos principales tralados se llamaron "El Tratado Multilateral de Libre Comercio e Inlegración Económica" (1958) y el "Tratado General de Integración Económica" (1960).

11. Ver Viclor Bulmer-Thomas, The Political Economy of Central America since 1920 (Cambridge y Nueva York: Cambridge University Press, 1986), pág. 195 y siguientes.

12. Se hizo la encuesta en los últimos meses del gobierno de Guillermo Endara, unos meses antes de la elección de Ernesto Pérez Valladares.

13. Ver Institulo Universitario de Opinión Pública, Los salvadoreños evalúan los dos años de gobierno de Calderón Sol. Estudios Cenlroamericanos, 571-572, mayo-junio 1996.

14. Karnes, entre muchos otros autores, no deja de mencionar la posibilidad de actitudes racistas de los costarricenses hacia los otros centroamericanos.

15. Esto implica que entre el $61 \%$ de costarricenses apoyando a la integración regional, la distribución de respuestas incluyó más casos de "apoyo" y menos de "apoyo fuerte"; mientras que en El Salvador, la distribución de los que apoyan a la integración regional estaba distribuida de forma más pareja entre las dos calegorias de 
respuesta positiva (de análisis de los autores no incluidos en este articulo).

16. Si se agregan las respuestas "no sabe" a las respuestas de "ninguna" ventaja o desventaja, la razón de los "sin desventajas percibidas" a los "sin ventajas percibidas" todavía es más favorable en El Salvador (70:18.9 ó 3.7:1) que en Costa Rica (49:27.3 6 1.79:1).

17. Al hacer este comentario, quisiéramos hacer notar la existencia de debates serios sobre la calidad de la democracia lograda en Costa Rica, tanto entre los mismos costarricenses como entre otros observadores. Sin embargo, la alternación del poder entre dos tendencias desde los años cincuenta, la mejor protección -no la absoluta prolección- de los derechos humanos en Costa Rica y la ausencia de gobiemos militares requiere un reconocimiento sobre el grado de democracia logrado allá.

18. En 1994, cuando se hicieron ambas encuestas, los costarricenses estaban negociando su propio tratado de libre comercio con México, dejando de lado a otros paises centroamericanos. En 1996, El Salvador era participante, junto con los miembros del "Triángulo de Norte", en tales negociaciones.

19. Donde las fracciones parlamentarias de un partido frecuentemente expresan sus críticas frente a un presidente de su propio partido. 